\title{
Increased efficiency of dye-sensitized solar cells by addition of rare earth oxide microparticles into a titania acceptor
}

Tulashi Luitel, ${ }^{\dagger}$ Kasun Fernando, ${ }^{\dagger}$ Brandon S. Tatum, ${ }^{\dagger}$ Bruce W. Alphenaar, ${ }^{\star}$ and Francis P. Zamborini ${ }^{*}, \dagger$

${ }^{\dagger}$ Department of Chemistry, University of Louisville, Louisville, KY 40292, United States

$\$$ Department of Electrical and Computer Engineering, University of Louisville, Louisville, KY 40292, United States

"Corresponding author:

Email: f.zamborini@louisville.edu; Tel: 502-852-6550; Fax: 502-852-8149 


\begin{abstract}
The addition of 400 micron scale rare-earth metal oxide particles to the $\mathrm{TiO}_{2}$ nanoparticle acceptor layer of a dye-sensitized solar cell (DSSC) dramatically increases the efficiency of the solar cell by $10-30 \%$. Oxidized neodymium powder, $\mathrm{Nd}_{2} \mathrm{O}_{3}$, combined with $\mathrm{TiO}_{2}$ nanoparticles forms a composite photoanode containing a wide range of $\mathrm{Nd}_{2} \mathrm{O}_{3}$ particle sizes. Based on absorbance measurements, the dye-uptake on the $\mathrm{Nd}_{2} \mathrm{O}_{3} / \mathrm{TiO}_{2}$ anode increases substantially compared to both a standard anode and to one made from a mixture of large and small $\mathrm{TiO}_{2}$ particles. Electrochemical impedance spectroscopy (EIS) shows a similar electron lifetime, but increased electron transport diffusion coefficient through the $\mathrm{Nd}_{2} \mathrm{O}_{3} / \mathrm{TiO}_{2}$ composite as compared to $\mathrm{TiO}_{2}$ only. This shows that the $\mathrm{Nd}_{2} \mathrm{O}_{3} / \mathrm{TiO}_{2}$ composite has a lower internal resistance for charge transport. This decrease in resistance, possibly due to the filling of trap states by the $\mathrm{Nd}_{2} \mathrm{O}_{3}$ valence or f-states, and increased dye uptake results in improved efficiency by simple incorporation of $\mathrm{Nd}_{2} \mathrm{O}_{3}$ powder.
\end{abstract}

Keywords: Rare earth oxide, hybrid solar cell, dye sensitized, photovoltaic, titanium dioxide 


\section{Introduction}

Since first described by Grätzel and co-workers, dye-sensitized solar cells (DSSCs) have been extensively investigated as a possible alternative to traditional semiconductor photovoltaic cells. DSSCs offer relatively high photo-conversion efficiencies while providing potential savings in fabrication costs compared to crystalline semiconductor photovoltaics [1-3]. In the DSSC, a photoanode consisting of dye-coated $\mathrm{TiO}_{2}$ nanoparticles is combined through an electrolyte redox couple to a counter electrode. The dye absorbs sunlight, and transfers photoexcited electrons to the conduction band of the $\mathrm{TiO}_{2}$, where the charge then diffuses to reach the electrode contact. Interfacial engineering [4] and surface modification of the oxide material are major strategies used to improve the efficiency of DSSCs [5]. This includes depositing a scattering layer of large size $\mathrm{TiO}_{2}$ particles on top of the active layer [6], controlling the haze of the film by incorporating larger $\mathrm{TiO}_{2}$ nanoparticles into the film $[7,8]$, chemically modifying the surface of the active layer with molecular linkers [9-11], coating the active layer with another metal oxide to form core/shell structures $[12,13]$, and doping the photoanodes with metal ions [14], metal nanoparticles [15, 16] or other dopants [17] or metal oxides [18].

Rare earth metals and oxides, well known for optical materials applications, show much promise as dopants to improve $\mathrm{TiO}_{2}$ for photovoltaic applications [19-21]. Rare earth doping has been observed to reduce the band-gap of $\mathrm{TiO}_{2}$ particles and increase the surface area of $\mathrm{TiO}_{2}$ nanoparticle films [22]. Rare earth doping improves $\mathrm{TiO}_{2}$ photocatalytic activity and photoelectrochemical response of $\mathrm{a} \mathrm{TiO}_{2}$ anode [23]. A hybrid organic/inorganic solar cell was demonstrated in which the $\mathrm{TiO}_{2}$ was completely replaced by rare earth oxide [24]. In DSSCs, a 
number of studies have shown that incorporation of a rare earth dopant in the photoanode can improve the cell efficiency [21, 25-32]. The rare earth material is usually incorporated from the rare earth salt precursor into the $\mathrm{TiO}_{2}$ nanostructures during synthesis $[25,28,30,31,33]$, sometimes as a core/shell structure [31], but has also been incorporated by soaking a prepared $\mathrm{TiO}_{2}$ photoanode into a rare earth salt solution followed by calcination [29] or by mixing rare earth nanoparticles with $\mathrm{TiO}_{2}$ nanoparticles followed by film preparation and calcination [27]. Improvements are often not well understood, but have been attributed to increased dye coverage [19, 34], improved electron injection [28, 30, 35], decreased recombination [19, 28, 34], reduction of trap states [35, 36], or increased electron diffusion $[19,28,34,35]$. There is considerable variation in results. For example, $\mathrm{Y}$ and Nd have been shown to both enhance [35, 37] and decrease $[19,36]$ the efficiency in different reports. Another type of material involves upconverting [38-44], downconverting [25, 40, 45-50], or dual-mode [51] luminescent rare earth nanostructures, which allow improved light collection efficiency when incorporated into the $\mathrm{TiO}_{2}$ photoanode in DSSCs. They can also help improve efficiency through light scattering [39, $43,50,52]$, altering the energy level of the $\mathrm{TiO}_{2}[43,48,53]$, or by reducing recombination processes $[47,54,55]$ at the $\mathrm{TiO}_{2} /$ electrolyte interface. Overall, the maximum efficiencies are in the $9-10 \%$ range for dye-sensitized $\mathrm{TiO}_{2}$ photoanodes doped with rare earth materials $[29,44$, 55]. Qin et al. recently reported $11.2 \%$ efficiency with a perovskite-based solar cell by incorporating $0.5 \% \mathrm{Y}$ into the $\mathrm{TiO}_{2}$ layer [56].

While the results of rare earth doping are certainly promising, the incorporation procedures have been limited, the improvements vary significantly and are the reasons for the improvement are not very well understood. A more systematic approach is needed for further, reproducible improvement through optimization of the rare earth doping element, the concentration, and 
incorporation method. A better fundamental understanding of the material properties and enhancement mechanism is also needed to make significant advancements in this area. In this article, we add to this knowledge base by reporting on a dramatically different method for incorporating rare earth materials into a traditional $\mathrm{TiO}_{2}$ photoanode of a DSSC. Here, 400 micron scale $\mathrm{Nd}_{2} \mathrm{O}_{3}$ "mesoscale" particles (powder) are mixed directly with the $\mathrm{TiO}_{2}$ nanometer scale colloids to form the photoanode. The film created in this manner is highly non-uniform and contains a large range of particle sizes. Despite this simple and crude method of rare earth doping, absorbance measurements show that the $\mathrm{Nd}_{2} \mathrm{O}_{3} / \mathrm{TiO}_{2}$ composite film takes-up $28 \%$ more dye than the standard $\mathrm{TiO}_{2}$ film and that the efficiency of DSSCs made with the composite anodes improves substantially by 10 to $30 \%$. Decreasing the dye coverage of the composite electrode to match that of the standard electrode still results in a substantial increase in efficiency, suggesting that improved transport properties contribute significantly to the improved efficiency. Importantly, this work lays the groundwork for future studies exploring other strategies of incorporating rare earth elements into $\mathrm{TiO}_{2}$ in the solid phase, which may lead to improvements in enhancement, greater device reproducibility, and a better understanding of the enhancement mechanism.

\section{Experimental}

\subsection{Photoanode Preparation}

Fluorine doped tin oxide (FTO) coated glass slides were solvent cleaned, and then soaked in $40 \mathrm{mM} \mathrm{TiCl}_{4}$ solution at $70{ }^{\circ} \mathrm{C}$ for $30 \mathrm{~min}$. The slides were masked with adhesive tape to create a $0.25 \mathrm{~cm}^{2}$ window. Dyesol $\mathrm{TiO}_{2}$ paste (DSL $18 \mathrm{NR}-\mathrm{T}$ or $30 \mathrm{NRD}$ ) was then deposited using the 
doctor blade method, and this process was repeated to obtain a film thickness of approximately $8.8 \mu \mathrm{m}$. In the highest efficiency cells, an additional 3-4 $\mu \mathrm{m}$ thick scattering layer of 200-400 $\mathrm{nm} \mathrm{TiO}_{2}$ particles (WER-2) was also deposited. The paste was sintered at $500{ }^{\circ} \mathrm{C}$ for $1 \mathrm{~h}$, post treated with $\mathrm{TiCl}_{4}$ and then sintered again at $500{ }^{\circ} \mathrm{C}$ for $1 \mathrm{~h}$. For the composite electrodes, 40 mesh oxidized Nd powder (Alfa Aesar) was ground finely with the $\mathrm{TiO}_{2}$ paste in a chosen weight ratio and then deposited on the FTO slides in the first layer using the procedure described above. The second layer was performed with the Dyesol $\mathrm{TiO}_{2}$ paste only as described above. The percentage of $\mathrm{Nd}$ reported in the main text refers to the percent $\mathrm{Nd}$ in the first layer only. Sensitization of the $\mathrm{FTO} / \mathrm{TiO}_{2}$ and $\mathrm{FTO} / \mathrm{TiO}_{2}-\mathrm{Nd}_{2} \mathrm{O}_{3}$ electrodes was achieved by immersing the electrodes into a $0.3 \mathrm{mM}$ solution of Dyesol N719 dye in a 1:1 mixture of acetonitrile and $t$ butanol. Counter electrodes with holes made by $0.8 \mathrm{~mm}$ diamond tip drilling bit (UKAM, USA) were created by coating a cleaned FTO slide with a drop of Platisol and heating to $500{ }^{\circ} \mathrm{C}$ for 20 min. Both electrodes were painted by hot melted indium chunk from the contact to the edges to produce good electrical contact. Sandwich cells were prepared by inserting plastic ionomer (Surlyn) between the working electrode and counter electrode; heating at $118{ }^{\circ} \mathrm{C}$ for one minute in a thermal press (model number, MPRESS912, HeatPress Nation, USA). For more improvement in hermetical sealing of devices, epoxy was placed all around the contact joining the photoanode and the counter electrode. A drop of electrolyte was placed on the top of hole made in the counter electrode. If sealing was good, the drop would not go into the device because of the air pressure produced by the trapped air in between the counter electrode and photoanode. The whole device was kept in a small vacuum box, and air was pumped out for $15 \mathrm{~s}$. When air was pumped in, the electrolyte filled the vacuum space or the porous part of the dyecoated photoanode. The drilled hole was then filled with liquid Surlyn sealant again, and on the 
top of it, a drop of melted Crystalbond adhesive wax (Ted Pella, USA) was applied to seal the hole. Epoxy was placed on top of the cooled wax

\subsection{Photoelectrochemical Measurements}

For photoelectrochemical measurements, the cells were illuminated with simulated $1.5 \mathrm{AM}$ solar light (Newport Oriel) with an intensity of $100 \mathrm{~mW} / \mathrm{cm}^{2}(1 \mathrm{Sun})$. The intensity of the light was set based on the voltage response of a commercially purchased, calibrated $1 \mathrm{~cm}^{2}$ reference silicon solar cell from Abet Technologies, Inc., USA with in-built KG5 filter (uncertainty = 8\%). The light source was set to 1 Sun by adjusting the light intensity until the reference silicon solar cell gave a reading of $100 \mathrm{mV}$ as measured by a voltmeter. A homemade optical sample holder was used to mount the reference silicon solar cell. After setting the light intensity, the reference silicon solar cell was replaced with the fabricated dye-sensitized solar cell (DSSC) under study in the same location at the same distance from the light source as dictated by the optical holder. The devices were masked by sticky black paper tape with an open window area of $0.16 \mathrm{~cm}^{2}$ prepared by a laser printer. Black electrical tape was used to seal all edges of the DSSC devices in order to prevent light piping. Current-voltage curves were obtained with a Model 273A EG \& G Princeton Applied Research Potentiostat by scanning the voltage from $0.2 \mathrm{~V}$ to $-1.0 \mathrm{~V}$ at a scan rate of $20 \mathrm{mV} / \mathrm{s}$ to the cells and measuring the current. The same device measured at least 5 times per day over a 7 day period gave the same results with less than $4 \%$ relative standard deviation, showing very good reproducibility of the measurement system.

\subsection{Other Characterization}


Absorbance spectra of the real photoanodes were measured with a Varian Cary 50 Win UVVIS spectrophotometer and diffuse reflectance spectroscopic (DRS) measurements were performed using a Lambda 950 PerkinElmer DRS Instrument. Electrochemical Impedance Spectroscopic (EIS) measurements were performed using a CHI 660a electrochemical workstation. A $10 \mathrm{mV}$ AC perturbation at open circuit voltage was applied between the photoanode and the platinum counter electrode with a frequency range of $1000 \mathrm{kHz}$ to $5 \mathrm{mHz}$. The photoanodes were maintained at the open circuit voltage by illuminating with white light (35 $\mathrm{mW} / \mathrm{cm}^{2}$ ) produced from an optical fiber (Fiber Optic Illuminator Model 190, Dolan-Jenner).

\section{Results and discussion}

Figure 1 compares images of traditional $\mathrm{TiO}_{2}$ nanoparticle films (A, C, and E) and those created by combining $5 \%$ oxidized 40 mesh $\mathrm{Nd}$ powder with the $\mathrm{TiO}_{2}$ nanoparticles $(\mathrm{B}, \mathrm{D}$, and F). Figure 1(A) and (B) show optical images, while the others show electron microscope images at increasing magnification. The $\mathrm{Nd}_{2} \mathrm{O}_{3}$ particles are clearly visible as large protrusions within the $\mathrm{TiO}_{2}$ nanoparticle film. Grinding of the mixture produces a distribution of $\mathrm{Nd}_{2} \mathrm{O}_{3}$ particles from 100 s of nm up to 100 microns. Increased magnification reveals that cracks have formed near the $\mathrm{Nd}_{2} \mathrm{O}_{3}$ particles during sintering. Fig. 1(D) and (F) show that the nanoscale $\mathrm{TiO}_{2}$ particles fill the cracks, along with the region on top of the $\mathrm{Nd}_{2} \mathrm{O}_{3}$ mesoparticles. Optical reflectance measurements of the $\mathrm{TiO}_{2}$ and composite electrodes (Supplementary Data, Figure S1) show that the $\mathrm{TiO}_{2}$ band edge is not affected by the $\mathrm{Nd}_{2} \mathrm{O}_{3}$ particles, however, additional features due to $\mathrm{Nd}_{2} \mathrm{O}_{3}$ optical transitions are observed [57].

Six batches of photoanodes were fabricated and characterized. Each batch contains both standard $\mathrm{TiO}_{2}$ photoanodes, and photoanodes mixed with $5 \%$ (by weight) oxidized 40 mesh $\mathrm{Nd}$ 
powder. Following measurements, results from multiple (from 2 to 4 ) devices of the same type in a single batch are averaged together. Figures $2 \mathrm{~A}$ and $2 \mathrm{~B}$ show the current density versus bias for the $\mathrm{Nd}_{2} \mathrm{O}_{3}$ modified devices and unmodified devices, respectively. Each color corresponds to a different batch (the results from batch 2 are left out for clarity). The voltage axis is reversed between the two plots to allow for easier comparison of the data. There is considerable variation in the current-voltage characteristics between different batches of solar cells. However, for each batch, the short circuit current is substantially higher for the samples containing the $\mathrm{Nd}_{2} \mathrm{O}_{3}$ than for the standard DSSCs. Figures 2C-F are box plots summarizing the photoelectrochemical parameters measured for the $\mathrm{Nd}_{2} \mathrm{O}_{3}$-modified (solid boxes) and unmodified (hashed boxes) photoanodes for all six batches. As shown in Fig. 2C (and described above) the short circuit current density is higher for the $\mathrm{Nd}_{2} \mathrm{O}_{3}$ modified samples than for the unmodified samples in each batch. This produces the observed efficiency increase shown in Fig. 2D; the improvement in efficiency due to $\mathrm{Nd}_{2} \mathrm{O}_{3}$ modification ranges from about 10 to $30 \%$. Changes in the fill factor (Fig. 2E) and open circuit voltage (Fig. 2F) are small and inconsistent among the different batches, suggesting that the $\mathrm{Nd}_{2} \mathrm{O}_{3}$ has little impact on these parameters. Table $\mathrm{S} 1$ in the supporting information summarizes the photoelectrochemical measurements and dark current onset voltage for all of the batches of $\mathrm{Nd}_{2} \mathrm{O}_{3}$ modified and unmodified devices. The dark current onset voltage fluctuates in a similar manner between the modified and unmodified samples, suggesting that the recombination kinetics are similar in both types of photoanodes. Further experiments show that the $\mathrm{Nd}_{2} \mathrm{O}_{3}$ modification does not negatively impact the device stability as long as it is sealed properly. Well-sealed $\mathrm{Nd}_{2} \mathrm{O}_{3}$ modified samples exhibit little change in the short circuit current and efficiency for up to 40 days (See Figure S2 of supplementary data). 
Photoelectrochemical measurements show that the efficiency of DSSCs with photoanodes modified with $\mathrm{Nd}_{2} \mathrm{O}_{3}$ is strongly dependent on the concentration of $\mathrm{Nd}_{2} \mathrm{O}_{3}$ by weight relative to the $\mathrm{TiO}_{2}$. In Figure 3, the current density versus bias is plotted for samples containing varying weight concentrations of $\mathrm{Nd}_{2} \mathrm{O}_{3}$ under 1.5 AM solar light. Both $5 \%$ and $20 \% \mathrm{Nd}_{2} \mathrm{O}_{3}$ concentration samples have higher efficiency than the $\mathrm{TiO}_{2}$ only sample, while above $20 \%$ the efficiency is reduced. The inset shows a plot of the efficiency as a function of the weight percentage of $\mathrm{Nd}_{2} \mathrm{O}_{3}$ mesh particles, indicating that the maximum efficiency occurs at $\sim 5 \%$ by weight. This set of data was obtained from a separate batch of samples from those shown in Figure 2.

To better understand the improved efficiency, optical absorbance measurements were performed on the composite and standard anode materials after soaking in dye for 24 hours. Figure $4 \mathrm{~A}$ shows the resulting absorbance spectra. Both $\mathrm{TiO}_{2}$ and $\mathrm{TiO}_{2}-5 \% \mathrm{Nd}_{2} \mathrm{O}_{3}$ samples show similar absorbance peaks due to the dye. The metal-to-ligand charge transfer (MLCT) band of the N719 dye appears at $538 \mathrm{~nm}$ in the pure $\mathrm{TiO}_{2}$ sample and at $544 \mathrm{~nm}$ in the sample with $5 \% \mathrm{Nd}_{2} \mathrm{O}_{3}$, a small red shift. The main influence of the $\mathrm{Nd}_{2} \mathrm{O}_{3}$ incorporation is to increase the magnitude of the dye absorbance by approximately $28 \%$, indicating that the $5 \% \mathrm{Nd}_{2} \mathrm{O}_{3} / \mathrm{TiO}_{2}$ hybrid film is able to uptake appreciably more dye than the standard sample. As shown in Figure $\mathrm{S} 3$ of supporting information, the increase in absorbance is maximized for $5 \% \mathrm{Nd}_{2} \mathrm{O}_{3}$ concentration, similar to the dependence on efficiency shown in Figure 3. Figure 4B shows the magnitude of absorbance of the MLCT band as a function of dye soaking time for both $5 \%$ $\mathrm{Nd}_{2} \mathrm{O}_{3}$ and pure $\mathrm{TiO}_{2}$. The absorption for the $5 \% \mathrm{Nd}_{2} \mathrm{O}_{3}$ sample rapidly increases above the pure $\mathrm{TiO}_{2}$ sample, reaching a maximum after approximately 5 hours of soaking. The same behavior occurred reproducibly for 3 samples of $5 \% \mathrm{Nd}_{2} \mathrm{O}_{3}$ and 3 samples of pure $\mathrm{TiO}_{2}$. Experiments 
involving the removal of dye from the $5 \% \mathrm{Nd}_{2} \mathrm{O}_{3}$ and pure $\mathrm{TiO}_{2}$ photoanodes followed by analysis of the dye quantity in solution agreed well with the transmission measurements from Figure $4 \mathrm{~A}$ and $4 \mathrm{~B}$.

As shown in Figure 1, the composite anodes have a distribution of $\mathrm{Nd}_{2} \mathrm{O}_{3}$ particle sizes with the formation of cracks nearby, where the $\mathrm{Nd}_{2} \mathrm{O}_{3}$ and cracks are coated with smaller $\mathrm{TiO}_{2}$ nanoparticles following sintering. It is possible that the cracked surface of the photoanode results in a larger surface area, and is able to adsorb a larger quantity of dye than a more uniform surface. To test this hypothesis, anodes were made that contained 400 micron scale $\mathrm{TiO}_{2}$ particles mixed with the $\mathrm{TiO}_{2}$ nanoparticles. As shown in supplementary data Figure $\mathrm{S} 4$, the surface of the all $\mathrm{TiO}_{2}$ composite electrode appears very similar to the surface of the $5 \% \mathrm{Nd}_{2} \mathrm{O}_{3}-$ $\mathrm{TiO}_{2}$ electrode, with cracks also forming around the larger particles. However, there is an insignificant increase in the MLCT band absorbance of the $\mathrm{TiO}_{2}$ composite electrode compared with the $\mathrm{TiO}_{2}$ nanoparticle electrode (Figure S4-C) and the efficiency of DSSCs made from the $\mathrm{TiO}_{2}$ composite electrodes is virtually identical to those made from the $\mathrm{TiO}_{2}$ nanoparticle electrodes (Figure S4-D). This shows that the ability to adsorb large amounts of dye is specific to rare earth oxide incorporation. It also shows that the mesoscale particles of $\mathrm{TiO}_{2}$ intermixed in the cathode do not function as an effective scattering layer [6] or improve the efficiency based on increased haze $[7,8]$ in our case, making these explanations for the improved efficiency in the $\mathrm{Nd}_{2} \mathrm{O}_{3}$ composite samples unlikely. Others have reported improved efficiency when mixing larger particles or powders of $\mathrm{TiO}_{2}$ of various shapes and sizes with nanoscale $\mathrm{TiO}_{2}$ nanoparticles [58-60], which has been attributed to increased dye loading, improved light collection, and improved electron transport, but we did not observe significant improvements for the addition of $5 \%$ microscale $\mathrm{TiO}_{2}$ under our experimental conditions. 
To determine whether the efficiency increase observed is mainly due to increased dye uptake, solar cells were prepared with $\mathrm{TiO}_{2}$ only and $\mathrm{TiO}_{2}-5 \% \mathrm{Nd}_{2} \mathrm{O}_{3}$ photoanodes that had the same dye coverage. Using the dye adsorption kinetics data in Figure $4 \mathrm{~B}$ as a guide, $5 \% \mathrm{Nd}_{2} \mathrm{O}_{3}$ anodes were soaked in dye for 2 hours, while pure $\mathrm{TiO}_{2}$ anodes were soaked for 2.5 hours. The resulting absorbance spectra for the two anodes are shown in Figure 4C. In this case, the MLCT band absorbance for the dye is virtually identical for the two different anodes, indicating that the dye coverage is also the same. Figure 4D shows the plots of current density versus bias in light for the two photoanodes with the same dye coverage. In both cases, the efficiency is appreciably lower than that observed for these photoanodes with full dye coverage using a 24 hour soak (Figure 2). However, the $5 \% \mathrm{Nd}_{2} \mathrm{O}_{3}$ anode still produced a significantly higher efficiency $(5.39 \%)$ than the pure $\mathrm{TiO}_{2}$ anode $(3.65 \%)$, even though the dye coverage was the same. This shows that dye coverage is not the only reason, and probably not the main reason, for the improved efficiency of the $\mathrm{TiO}_{2}-5 \% \mathrm{Nd}_{2} \mathrm{O}_{3}$ photoanodes compared to $\mathrm{TiO}_{2}$ only.

Figure 4 shows that the $\mathrm{Nd}_{2} \mathrm{O}_{3}$ mesoparticles incorporated into $\mathrm{TiO}_{2}$ not only increase dye uptake, but also somehow improve charge collection and transport through the photoanode. To further investigate the charge transport within the cell, we used electrochemical impedance spectroscopy (EIS). Figure 5A shows the EIS Nyquist plots for the same photoanodes whose J$\mathrm{V}$ plots are shown in Figure 3 and Figure 5B shows the corresponding Bode plots. In the Nyquist plots there are three distinct semi-circles. The left semi-circle denotes the high frequency window $(100 \mathrm{kHz}-500 \mathrm{~Hz})$ and measures charge transfer from the counter electrode to the electrolyte. The middle semi-circle corresponds to the medium frequency window (100 $\mathrm{Hz}-1 \mathrm{~Hz}$ ), and measures the $\mathrm{TiO}_{2} / \mathrm{Dye} /$ electrolyte or $\mathrm{TiO}_{2}-\mathrm{Nd}_{2} \mathrm{O}_{3} /$ Dye/electrolyte interface. The right semicircle corresponds to the low frequency window $(1 \mathrm{~Hz}-5 \mathrm{mHz})$ and is normally 
considered to measure diffusion of the electrolyte/redox couple $[61,62]$. There are three key features of the middle semi-circle region of the Nyquist plot [62]. First, the recombination kinetics can be estimated by the peak frequency from this central arc [62]. A low peak frequency is desired for slow recombination kinetics and long electron lifetimes. This enhances the collection efficiency of injected electrons. Second, the diameter of the semi-circle is indicative of the electron recombination resistance. Third, the shape of the arc is indicative of the ratio of electron recombination resistance to the resistance of electron diffusion through the $\mathrm{TiO}_{2}$ or $\mathrm{Nd}_{2} \mathrm{O}_{3} / \mathrm{TiO}_{2}$ film. A clear circular shape indicates that the former is much larger than the latter, which is desired for high efficiency cells [62]. As shown in Figure 5A, the smallest diameter semi-circle is observed for $5 \% \mathrm{Nd}_{2} \mathrm{O}_{3}$ followed by $0 \% \mathrm{Nd}_{2} \mathrm{O}_{3}, 50 \% \mathrm{Nd}_{2} \mathrm{O}_{3}$, and finally $75 \%$ $\mathrm{Nd}_{2} \mathrm{O}_{3}$. This could indicate that electron recombination resistance is the lowest in the $5 \% \mathrm{Nd}_{2} \mathrm{O}_{3}$ films, which is not desirable. However, the Bode plots in Figure 5B show that the peak frequency for the $5 \%$ and $0 \% \mathrm{Nd}_{2} \mathrm{O}_{3}$ are very similar (14 and $12 \mathrm{~Hz}$, respectively), indicating similar electron recombination kinetics for those two films. The peak frequency of the 50\% $\mathrm{Nd}_{2} \mathrm{O}_{3}$ and $75 \% \mathrm{Nd}_{2} \mathrm{O}_{3}$ films are clearly large, indicative of faster recombination kinetics and shorter electron lifetimes, which explains why those films exhibit lower efficiencies. Considering that the recombination kinetics are similar for the $5 \%$ and $0 \% \mathrm{Nd}_{2} \mathrm{O}_{3}$ photoandoes, it is more desirable to have a smaller semi-circle (lower impedance) in the middle frequency region. This feature (smaller semi-circle in middle frequency) in EIS has been demonstrated previously for DSSCs as a function of increasing dye coverage [63] and increasing $\mathrm{TiO}_{2}$ thickness $[62,64,65]$, as long as the thickness does not exceed the electron diffusion length. Increased dye coverage can lead to a lower impedance in this region when going from very low coverage to full monolayer [63], which has been attributed to recombination occurring through 
the dye molecule, but the $\mathrm{V}_{\mathrm{OC}}$ also increases. However, with almost full initial monolayer coverage, a further improvement in coverage by a cycling procedure led to higher impedance in this region due to a more passivating dye layer, which improved efficiency by blocking recombination [66]. In both cases, increased dye coverage accompanied an increase in open circuit voltage, which we did not observe in our case.

The open circuit voltage is not significantly different and the dark current data and Bode plots both reveal that the recombination kinetics are very similar when comparing $\mathrm{TiO}_{2}$ and $5 \%$ $\mathrm{Nd}_{2} \mathrm{O}_{3} / \mathrm{TiO}_{2}$ photoanodes. Accordingly, we attribute the lower impedance in the middle frequency regime to lower resistance to electron diffusion through the $5 \%-\mathrm{Nd}_{2} \mathrm{O}_{3} / \mathrm{TiO}_{2}$ photoanode as compared to $\mathrm{TiO}_{2}$ only, leading to a larger electron diffusion length. A lower impedance in this regime, but similar frequency in a Bode plot and similar open circuit voltage was also observed previously as the thickness of a $\mathrm{TiO}_{2}$ film increased [62], which also resulted in a larger effective electron diffusion coefficient.The lower resistance to electron diffusion through the mesoporous film indicates that the presence of $\mathrm{Nd}_{2} \mathrm{O}_{3}$ either reduces trapping kinetics, increases detrapping kinetics, or decreases the number of trap states in $\mathrm{TiO}_{2}$. Since a decrease in the number of trap states should increase the electron lifetime, which did not occur in our case, our data is most consistent with the $\mathrm{Nd}_{2} \mathrm{O}_{3}$ favorably altering the trapping and detrapping kinetics [64]. This would instead lead to a larger electron diffusion coefficient and longer diffusion length as observed.

To understand how the $\mathrm{Nd}_{2} \mathrm{O}_{3}$ might alter the trapping and detrapping kinetics, consider the simple energy diagram of the $\mathrm{Dye} / \mathrm{TiO}_{2} / \mathrm{Nd}_{2} \mathrm{O}_{3}$ system in the inset to Figure $5 \mathrm{~A}$. $\mathrm{The} \mathrm{Nd}_{2} \mathrm{O}_{3}$ valence band edge (filled $\mathrm{f}$ and spd states) has been calculated to lie well within the $\mathrm{TiO}_{2}$ band gap, while the conduction band (spd states), and empty f-band lie above the band edge of the dye 
LUMO level [67-69]. It is unlikely that the $\mathrm{Nd}_{2} \mathrm{O}_{3}$ would provide an additional transport path for the photo excited electrons from the dye since the conduction band energy is too high, and the fstates, while available, are localized states with high transport resistance. However, it is known that $\mathrm{TiO}_{2}$ contains mid-gap surface trapping states that capture injected charge from the dye and lower the efficiency. It is possible that the $\mathrm{Nd}_{2} \mathrm{O}_{3}$ acts to occupy these states (not eliminate) through charge transfer from photoexcited states corresponding to the transitions shown in Figure $\mathrm{S}$, or from the $\mathrm{Nd}_{2} \mathrm{O}_{3}$ valence band. Injected electrons from the photo excited dye can then transfer through the $\mathrm{TiO}_{2}$ without being trapped [70]. This mechanism is highly speculative at this time and more work is needed to definitively rule out possible effects of dye coverage, improved light scattering, or other mechanisms. We also note that $\mathrm{Nd}$ likely occupies a larger volume of the film than that shown by the location of the large microscale $\mathrm{Nd}_{2} \mathrm{O}_{3}$ particles in the images, since $\mathrm{Nd}$ may diffuse into the $\mathrm{TiO}_{2}$ particles during the grinding and sintering process. Spatial elemental characterization of the films and incorporation of nanoscale Nd particles into the photoanodes will allow us to better quantify and control the extent of $\mathrm{Nd}$ incorporation into $\mathrm{TiO}_{2}$ in future studies.

\section{Conclusions}

In conclusion, a dramatically improved efficiency has been observed in a DSSC incorporating a composite working electrode composed of a simple mixture of $\mathrm{TiO}_{2}$ nanoparticles and $\mathrm{Nd}_{2} \mathrm{O}_{3}$ mesoscale particles (Nd powder). The addition of the large rare earth oxide particles greatly increases the dye uptake of the film and reduces the electron diffusion resistance through the $\mathrm{TiO}_{2}$ film to the FTO contact. It is shown that the incorporation of rare earth oxides into photoanodes is a promising approach to improve the efficiency of DSSCs, and 
through variation in material, incorporation method, and particle size it is anticipated that further improvements are possible.

\section{Acknowledgements}

This research was supported by the U.S. Department of Energy (EPSCOR) DE-FG0207ER46375 and the University of Louisville. We acknowledge Dr. Mahendra Sunkara and Dr. Thad Druffel in the Conn Center for Renewable Energy Research at the University of Louisville for helpful discussions and use of device measuring equipment. T.L. would like to acknowledge Prof. Michael Grätzel and Prof. Carole Grätzel from Ecole Polytechnique Federale De Lausanne, EPFL, Switzerland, for discussions about the devices and fabrication techniques to optimize efficiency. We also want to extend thanks to Steve Riley for help in fabricating the fine holes on the counter electrodes and to Aiqin Fang for helping to obtain optical microscope images of the photoanodes.

\section{Supplementary Data:}

The reflectivity of the photoanodes, a summary table of results from all devices, results of a stability test on a well-sealed device, and characterization of $\mathrm{TiO}_{2}$ meso/nano samples is included in the supplementary data.

\section{References}

[1] B. O'Regan, Gratzel, M., A low-cost, high-efficiency solar cell based on dye-sensitized colloidal $\mathrm{TiO}_{2}$ films, Nature, 353 (1991) 737-740.

[2] H. Tsubomura, M. Matsumura, Y. Nomura, T. Amamiya, Dye sensitised zinc oxide: aqueous electrolyte: platinum photocell, Nature, 261 (1976) 402-403.

[3] M. Gratzel, Photoelectrochemical Cells, Nature, 414 (2001) 338 - 344. 
[4] S. Zhang, X. Yang, C. Qin, Y. Numata, L. Han, Interfacial engineering for dye-sensitized solar cells, J. Mater. Chem. A, 2 (2014) 5167-5177.

[5] J.Z. Li, F.T. Kong, G.H. Wu, Y. Huang, W.C. Chen, S.Y. Dai, $\mathrm{TiO}_{2} /$ dye/electrolyte interface modification for dye-sensitized solar cells, Acta Phys.-Chim. Sin., 29 (2013) 1851-1864.

[6] P. Wang, S.M. Zakeeruddin, J.E. Moser, R. Humphry-Baker, P. Comte, V. Aranyos, A. Hagfeldt, M.K. Nazeeruddin, M. Gratzel, Stable new sensitizer with improved light harvesting for nanocrystalline dye-sensitized solar cells, Adv. Mater., 16 (2004) 1806-1811.

[7] Y. Chiba, Islam, A., Watanabe, Y., Komiya, R., Koide N., Han, L., Dye-sensitized solar cells with conversion efficiency of 11.1\%, Jpn. J. Appl. Phys., 45 (2006) L638-L640.

[8] Y. Chiba, A. Islam, R. Komiya, N. Koide, L.Y. Han, Conversion efficiency of $10.8 \%$ by a dye-sensitized solar cell using a $\mathrm{TiO}_{2}$ electrode with high haze, Appl. Phys. Lett., 88 (2006) 223505.

[9] J. Zhang, G. Yang, Q. Sun, J. Zheng, P. Wang, Y. Zhu, X. Zhao, The improved performance of dye sensitized solar cells by bifunctional aminosilane modified dye sensitized photoanode, J. Renewable Sustainable Energy, 2 (2010) 013104.

[10] T. Luitel, F.P. Zamborini, Covalent modification of photoanodes for stable dye-sensitized solar cells, Langmuir, 29 (2013) 13582-13594.

[11] B. Pandit, T. Luitel, D.R. Cummins, A.K. Thapa, T. Druffel, F. Zamborini, J. Liu, Spectroscopic investigation of photoinduced charge-transfer processes in $\mathrm{FTO} / \mathrm{TiO}_{2} / \mathrm{N} 719$ photoanodes with and without covalent attachment through silane-based linkers, J. Phys. Chem. A, 117 (2013) 13513-13523.

[12] K.M.P. Bandaranayake, S.M.K. Indika, W.P.M.G.M. Prasad, K. Tennakone, Dye-sensitized solar cells made from nanocrystalline $\mathrm{TiO}_{2}$ films coated with outer layers of different oxide materials, Coord. Chem. Rev., 248 (2004) 1277-1281.

[13] Y. Diamant, S. Chappel, S.G. Chen, O. Melamed, A. Zaban, Core-shell nanoporous electrode for dye sensitized solar cells: the effect of shell characteristics on the electronic properties of the electrode, Coord. Chem. Rev., 248 (2004) 1271-1276.

[14] S. Wang, Z. Yu, X. Zhang, D. Ma, Nd, N-doped $\mathrm{TiO}_{2}$ anode effect on performance of dyesensitized solar cells, Optoelectron. Adv. Mater., Rapid Commun., 7 (2013) 549-552.

[15] H. Choi, W.T. Chen, P.V. Kamat, Know thy nano neighbor.plasmonic versus electron charging effects of metal nanoparticles in dye-sensitized solar cells, ACS Nano, 6 (2012) 44184427.

[16] M. Ihara, K. Tanaka, K. Sakaki, I. Honma, K. Yamada, Enhancement of the absorption coefficient of cis-(NCS) $)_{2}$ Bis(2,2'-bipyridyl-4,4'-dicarboxylate)ruthenium(II) dye in dyesensitized solar cells by a silver island film, J. Phys. Chem. B, 101 (1997) 5153-5157.

[17] Y.A. Xie, N. Huang, Y.M. Liu, W.W. Sun, H.F. Mehnane, S.J. You, L.Y. Wang, W. Liu, S.S. Guo, X.Z. Zhao, Photoelectrodes modification by N doping for dye-sensitized solar cells, Electrochim. Acta, 93 (2013) 202-206.

[18] S.P. Berglund, S. Hoang, R.L. Minter, R.R. Fullon, C.B. Mullins, Investigation of 35 elements as single metal oxides, mixed metal oxides, or dopants for titanium dioxide for dyesensitized solar cells, J. Phys. Chem. C, 117 (2013) 25248-25258.

[19] M. Zalas, Gadolinium-modified titanium oxide materials for photoenergy applications: a review, J. Rare Earths, 32 (2014) 487-495.

[20] X.Y. Huang, S.Y. Han, W. Huang, X.G. Liu, Enhancing solar cell efficiency: the search for luminescent materials as spectral converters, Chem. Soc. Rev., 42 (2013) 173-201. 
[21] G.F. Wang, Q. Peng, Y.D. Li, Lanthanide-doped nanocrystals: synthesis, optical-magnetic properties, and applications, Acc. Chem. Res., 44 (2011) 322-332.

[22] V. Gomez, A.M. Balu, J.C. Serrano-Ruiz, S. Irusta, D.D. Dionysiou, R. Luque, J.

Santamaría, Microwave-assisted mild-temperature preparation of neodymium-doped titania for the improved photodegradation of water contaminants, Appl. Catal., A, 441-442 (2012) 47-53. [23] R. Kralchevska, M. Milanova, D. Hristov, A. Pintar, D. Todorovsky, Synthesis, characterization and photocatalytic activity of neodymium, nitrogen and neodymium-nitrogen doped $\mathrm{TiO}_{2}$, Mater. Res. Bull., 47 (2012) 2165-2177.

[24] K. Fernando, B. Pandit, J. Liu, B.W. Alphenaar, Charge transfer in rare earth oxide hybrid solar cells, Chem. Phys. Lett., 592 (2014) 155-159.

[25] H. Hafez, M. Saif, M.S.A. Abdel-Mottaleb, Down-converting lanthanide doped $\mathrm{TiO}_{2}$ photoelectrodes for efficiency enhancement of dye-sensitized solar cells, J. Power Sources, 196 (2011) 5792-5796.

[26] S. Wang, Z.C. Yu, X.J. Zhang, D. Ma, Nd, N-doped $\mathrm{TiO}_{2}$ anode effect on performance of dye-sensitized solar cells, Optoelectron. Adv. Mater., Rapid Commun., 7 (2013) 549-552.

[27] J. Wu, G. Xie, J. Lin, Z. Lan, M. Huang, Y. Huang, Enhancing photoelectrical performance of dye-sensitized solar cell by doping with europium-doped yttria rare-earth oxide, J. Power Sources, 195 (2010) 6937-6940.

[28] Q.H. Yao, J.F. Liu, Q. Peng, X. Wang, Y.D. Li, Nd-doped $\mathrm{TiO}_{2}$ nanorods: preparation and application in dye-sensitized solar cells, Chem-Asian J., 1 (2006) 737-741.

[29] M. Zalas, M. Klein, The influence of titania electrode modification with lanthanide ions containing thin layer on the performance of dye-sensitized solar cells, Int. J. Photoenergy, 2012 (2012) 927407.

[30] J. Zhang, W. Peng, Z. Chen, H. Chen, L. Han, Effect of cerium doping in the $\mathrm{TiO}_{2}$ photoanode on the electron transport of dye-sensitized solar cells, J. Phys. Chem. C, 116 (2012) 19182-19190.

[31] J. Zhang, H. Shen, W. Guo, S. Wang, C. Zhu, F. Xue, J. Hou, H. Su, Z. Yuan, An upconversion $\mathrm{NaYF}_{4}: \mathrm{Yb}^{3+}, \mathrm{Er}^{3+} / \mathrm{TiO}_{2}$ core-shell nanoparticle photoelectrode for improved efficiencies of dye-sensitized solar cells, J. Power Sources, 226 (2013) 47-53.

[32] F.T. Li, Y.Z. Gu, Improvement of performance of dye-sensitized solar cells by doping $\operatorname{Er}_{2} \mathrm{O}_{3}$ into $\mathrm{TiO}_{2}$ electrodes, Mater. Sci. Semicond. Process, 15 (2012) 11-14.

[33] C.P. Sibu, S.R. Kumar, P. Mukundan, K.G.K. Warrier, Structural modifications and associated properties of lanthanum oxide doped sol-gel nanosized titanium oxide, Chem. Mater., 14 (2002) 2876-2881.

[34] A.A. Khan, J. Islam, S.G. Ansari, H. Fouad, Z.A. Ansari, Effect of neodymium on the photoconversion efficiency of $\mathrm{TiO}_{2}$ based dye sensitized solar cells, J. Mater. Sci.-Mater. Electron., 26 (2015) 1737-1742.

[35] S. Shogh, R. Mohammadpour, A.I. Zad, N. Taghavinia, Improved photovoltaic performance of nanostructured solar cells by neodymium-doped $\mathrm{TiO}_{2}$ photoelectrode, Mater. Lett., 159 (2015) 273-275.

[36] C. Cavallo, A. Salleo, D. Gozzi, F. Di Pascasio, S. Quaranta, R. Panetta, A. Latini, Solid solutions of rare earth cations in mesoporous anatase beads and their performances in dyesensitized solar cells, Sci. Rep., 5 (2015) 16785.

[37] B. Zhao, J. Wang, H. Li, H. Wang, X. Jia, P. Su, The influence of yttrium dopant on the properties of anatase nanoparticles and the performance of dye-sensitized solar cells, Phys. Chem. Chem. Phys., 17 (2015) 14836-14842. 
[38] J. Chang, Y.H. Ning, S.L. Wu, W.B. Niu, S.F. Zhang, Effectively utilizing NIR light using direct electron injection from up-conversion nanoparticles to the $\mathrm{TiO}_{2}$ photoanode in dyesensitized solar cells, Adv. Funct. Mater., 23 (2013) 5910-5915.

[39] L.L. Liang, Y.M. Liu, C.H. Bu, K.M. Guo, W.W. Sun, N. Huang, T. Peng, B. Sebo, M.M. Pan, W. Liu, S.S. Guo, X.Z. Zhao, Highly uniform, bifunctional core/double-shell-structured$\mathrm{NaYF}_{4}: \mathrm{Er}^{3+}, \mathrm{Yb}^{3+} @ \mathrm{SiO}_{2} @ \mathrm{TiO}_{2}$ hexagonal sub-microprisms for high-performance dye sensitized solar cells, Adv. Mater., 25 (2013) 2174-2180.

[40] M.J. Lim, Y.N. Ko, Y.C. Kang, K.Y. Jung, Enhancement of light-harvesting efficiency of dye-sensitized solar cells via forming $\mathrm{TiO}_{2}$ composite double layers with down/up converting phosphor dispersion, RSC Adv., 4 (2014) 10039-10042.

[41] P. Ramasamy, J. Kim, Combined plasmonic and upconversion rear reflectors for efficient dye-sensitized solar cells, Chem. Commun., 50 (2014) 879-881.

[42] G.B. Shan, G.P. Demopoulos, Near-infrared sunlight harvesting in dye-sensitized solar cells Via the insertion of an upconverter- $\mathrm{TiO}_{2}$ nanocomposite layer, Adv. Mater., 22 (2010) 43734377.

[43] J.L. Wang, J.H. Wu, J.M. Lin, M.L. Huang, Y.F. Huang, Z. Lan, Y.M. Xiao, G.T. Yue, S. Yin, T. Sato, Application of $\mathrm{Y}_{2} \mathrm{O}_{3}: \mathrm{Er}^{3+}$ nanorods in dye-sensitized solar cells, ChemSusChem, 5 (2012) 1307-1312.

[44] J. Yu, Y.L. Yang, R.Q. Fan, D.Q. Liu, L.G. Wei, S. Chen, L. Li, B. Yang, W.W. Cao, Enhanced near-infrared to visible upconversion nanoparticles of $\mathrm{Ho}^{3+}-\mathrm{Yb}^{3+}-\mathrm{F}^{-}$tri-doped $\mathrm{TiO}_{2}$ and its application in dye-sensitized solar cells with $37 \%$ improvement in power conversion efficiency, Inorg. Chem., 53 (2014) 8045-8053.

[45] H. Hafez, J.H. Wu, Z. Lan, Q.H. Li, G.X. Xie, J.M. Lin, M.L. Huang, Y.F. Huang, M.S. Abdel-Mottaleb, Enhancing the photoelectrical performance of dye-sensitized solar cells using $\mathrm{TiO}_{2}: \mathrm{Eu}^{3+}$ nanorods, Nanotechnology, 21 (2010) 415201.

[46] S.Y. Chen, J.M. Lin, J.H. Wu, Improving photoelectrical performance of dye sensitized solar cells by doping $\mathrm{Y}_{2} \mathrm{O}_{3}: \mathrm{Tb}^{3+}$ nanorods, J. Mater. Sci.-Mater. Electron., 25 (2014) 2060-2065. [47] W. He, T.S. Atabaev, H.K. Kim, Y.H. Hwang, Enhanced sunlight harvesting of dyesensitized solar cells assisted with long persistent phosphor materials, J. Phys. Chem. C, 117 (2013) 17894-17900.

[48] Q.B. Li, J.M. Lin, J.H. Wu, Z. Lan, Y. Wang, F.G. Peng, M.L. Huang, Improving photovoltaic performance of dye-sensitized solar cell by downshift luminescence and p-doping effect of $\mathrm{Gd}_{2} \mathrm{O}_{3}: \mathrm{Sm}^{3+}$, J. Lumines., 134 (2013) 59-62.

[49] N.N. Yao, J.Z. Huang, K. Fu, S.Y. Liu, E. Dong, Y.H. Wang, X.J. Xu, M. Zhu, B.Q. Cao, Efficiency enhancement in dye-sensitized solar cells with down conversion material $\mathrm{ZnO}: \mathrm{Eu}^{3+}$, $\mathrm{Dy}^{3+}$, J. Power Sources, 267 (2014) 405-410.

[50] G. Zhu, X.J. Wang, H.L. Li, L.K. Pan, H.C. Sun, X.J. Liu, T. Lv, Z. Sun, $\mathrm{Y}_{3} \mathrm{Al}_{5} \mathrm{O}_{12}$ :Ce phosphors as a scattering layer for high-efficiency dye sensitized solar cells, Chem. Commun., 48 (2012) 958-960.

[51] Y. Li, K. Pan, G.F. Wang, B.J. Jiang, C.G. Tian, W. Zhou, Y. Qu, S. Liu, L. Feng, H.G. Fu, Enhanced photoelectric conversion efficiency of dye-sensitized solar cells by the incorporation of dual-mode luminescent $\mathrm{NaYF}_{4}: \mathrm{Yb}^{3+} / \mathrm{Er}^{3+}$, Dalton Trans., 42 (2013) 7971-7979.

[52] C.H. Han, H.S. Lee, K.W. Lee, S.D. Han, I. Singh, Synthesis of amorphous $\mathrm{Er}^{3+}-\mathrm{Yb}^{3+} \mathrm{co}^{-}$ doped $\mathrm{TiO}_{2}$ and its application as a scattering layer for dye-sensitized solar cells, Bull. Korean Chem. Soc., 30 (2009) 219-223. 
[53] J.L. Wang, J.M. Lin, J.H. Wu, M.L. Huang, Z. Lan, Y. Chen, S. Tang, L.Q. Fan, Y.F. Huang, Application of $\mathrm{Yb}^{3+}, \mathrm{Er}^{3+}$-doped yttrium oxyfluoride nanocrystals in dye-sensitized solar cells, Electrochimica Acta, 70 (2012) 131-135.

[54] J.H. Huang, P.Y. Hung, S.F. Hu, R.S. Liu, Improvement efficiency of a dye-sensitized solar cell using $\mathrm{Eu}^{3+}$ modified $\mathrm{TiO}_{2}$ nanoparticles as a secondary layer electrode, J. Mater. Chem., 20 (2010) 6505-6511.

[55] H. Yu, B.F. Xue, P.R. Liu, J.X. Qiu, W. Wen, S.Q. Zhang, H.J. Zhao, High-performance nanoporous $\mathrm{TiO}_{2} / \mathrm{La}_{2} \mathrm{O}_{3}$ hybrid photoanode for dye-sensitized solar cells, ACS Appl. Mater. Interfaces, 4 (2012) 1289-1294.

[56] P. Qin, A.L. Domanski, A.K. Chandiran, R. Berger, H.J. Butt, M.I. Dar, T. Moehl, N.

Tetreault, P. Gao, S. Ahmad, M.K. Nazeeruddin, M. Gratzel, Yttrium-substituted nanocrystalline $\mathrm{TiO}_{2}$ photoanodes for perovskite based heterojunction solar cells, Nanoscale, 6 (2014) 15081514.

[57] R. Bazzi, A. Brenier, P. Perriat, O. Tillement, Optical properties of neodymium oxides at the nanometer scale, J. Lumin., 113 (2005) 161-167.

[58] C.-J. Lin, W.-Y. Yu, S.-H. Chien, Effect of anodic $\mathrm{TiO}_{2}$ powder as additive on electron transport properties in nanocrystalline $\mathrm{TiO}_{2}$ dye-sensitized solar cells, Appl. Phys. Lett., 91 (2007) 233120.

[59] W.K. Tu, C.J. Lin, A. Chatterjee, G.H. Shiau, S.H. Chien, A novel nanocomposite $\mathrm{TiO}_{2}$ photoanode for highly efficient dye-sensitized solar cells, J. Power Sources, 203 (2012) 297-301. [60] H.M. Zhang, H. Yu, Y.H. Han, P.R. Liu, S.Q. Zhang, P. Wang, Y.B. Cheng, H.J. Zhao, Rutile $\mathrm{TiO}_{2}$. Microspheres with exposed nano-acicular single crystals for dye-sensitized solar cells, Nano Res., 4 (2011) 938-947.

[61] L. Han, N. Koide, Y. Chiba, T. Mitate, Modeling of an equivalent circuit for dye-sensitized solar cells, Appl. Phys. Lett., 84 (2004) 2433-2435.

[62] M. Adachi, M. Sakamoto, J. Jiu, Y. Ogata, S. Isoda, Determination of parameters of electron transport in dye-sensitized solar cells using electrochemical impedance spectroscopy, J. Phys. Chem. B, 110 (2006) 13872-13880.

[63] V. Johansson, L. Ellis-Gibbings, T. Clarke, M. Gorlov, G.G. Andersson, L. Kloo, On the correlation between dye coverage and photoelectrochemical performance in dye-sensitized solar cells, Phys. Chem. Chem. Phys., 16 (2014) 711-718.

[64] R. Kern, R. Sastrawan, J. Ferber, R. Strangl, J. Luther, Modeling and interpretation of electrical impedance spectra of dye solar cells operated under open-circuit conditions, Electrochim. Acta, 47 (2002) 4213-4225.

[65] I. Shin, H. Seo, M.-K. Son, J.-K. Kim, K. Prabakar, H.-J. Kim, Analysis of $\mathrm{TiO}_{2}$ thickness effect on characteristic of a dye-sensitized solar cell by using electrochemical impedance spectroscopy, Curr. Appl. Phys., 10 (2010) 5422-5424.

[66] G. Bazzan, J.R. Deneault, T.-S. Kang, B.E. Taylor, M.F. Durstock, Nanoparticle/dye interface optimization in dye-sensitized solar cells, Adv. Funct. Mater., 21 3268-3274.

[67] G.H. Dieke, Spectra and Energy Levels of Rare Earth Ions in Crystals, John Wiley \& Sons Inc., New York, NY, 1968.

[68] M.T. Greiner, L. Chai, M.G. Helander, W.-M. Tang, Z.-H. Lu, Transition metal oxide work functions: The influence of cation oxidation state and oxygen vacancies, Adv. Funct. Mater., 22 (2012) 4557-4568.

[69] L. Petit, A. Svane, Z. Szotek, W.M. Temmerman, First-principles study of rare-earth oxides, Phys. Rev. B, 72 (2005) 205118. 
[70] J. Zhang, T.F. Hughes, M. Steigerwald, L. Brus, R.A. Friesner, Realistic cluster modeling of electron transport and trapping in solvated $\mathrm{TiO}_{2}$ nanoparticles, J. Am. Chem. Soc., 134 (2012)

12028-12042.

\section{FIGURE CAPTIONS}

Figure 1. Images of the surface of $\mathrm{TiO}_{2}(\mathrm{~A}, \mathrm{C}$, and $\mathrm{E})$ and $5 \% \mathrm{Nd}_{2} \mathrm{O}_{3} / \mathrm{TiO}_{2}(\mathrm{~B}, \mathrm{D}$ and $\mathrm{F})$ photoanodes. A-B show optical microscope images while $\mathrm{C}-\mathrm{F}$ show scanning electron microscope images.

Figure 2. Current-density versus bias for $\mathrm{A}) \mathrm{Nd}_{2} \mathrm{O}_{3}$ modified and $\mathrm{B}$ ) unmodified photoanodes measured under 1.5 AM illumination. Different batches are shown as different colored lines: Batch 1(yellow), 2 (not shown), 3 (black), 4(blue), 5(green) and 6(red). (C-F) Box plots show C) short circuit current $D$ ) efficiency $E$ ) fill factor and F) open circuit voltage for each of the six batches. Solid blocks show $\mathrm{Nd}_{2} \mathrm{O}_{3}$ modified samples, hashed blocks show traditional unmodified samples.

Figure 3. Current-voltage characteristics of DSSCs made with anodes containing varying percent weight concentrations of $\mathrm{Nd}_{2} \mathrm{O}_{3}$. Inset: Efficiency as a function of $\mathrm{Nd}_{2} \mathrm{O}_{3}$ percent weight concentration.

Figure 4. A) UV-vis absorbance spectra for anodes made with $5 \% \mathrm{Nd}_{2} \mathrm{O}_{3} / \mathrm{TiO}_{2}$ composite anodes (green solid line) and traditional unmodified $\mathrm{TiO}_{2}$ anodes (red dashed line) soaked for 24 h. B) Absorbance as a function of dye soaking time. C) Absorbance after reduced dye soaking time of $2 \mathrm{~h}$ for $5 \% \mathrm{Nd}_{2} \mathrm{O}_{3} / \mathrm{TiO}_{2}$ and $2.5 \mathrm{~h}$ for $\mathrm{TiO}_{2}$. D) Current density-voltage characteristics in light for the dye coverage corresponding to $\mathrm{C}$ ).

Figure 5. A) Electrochemical impedance spectra for photoanodes containing different concentrations of $\mathrm{Nd}_{2} \mathrm{O}_{3}$. Inset: Band diagram showing trap filling in $\mathrm{TiO}_{2}$ due to $\mathrm{Nd}_{2} \mathrm{O}_{3}$ charge states. B) Bode plots corresponding to the impedance spectra in A) 


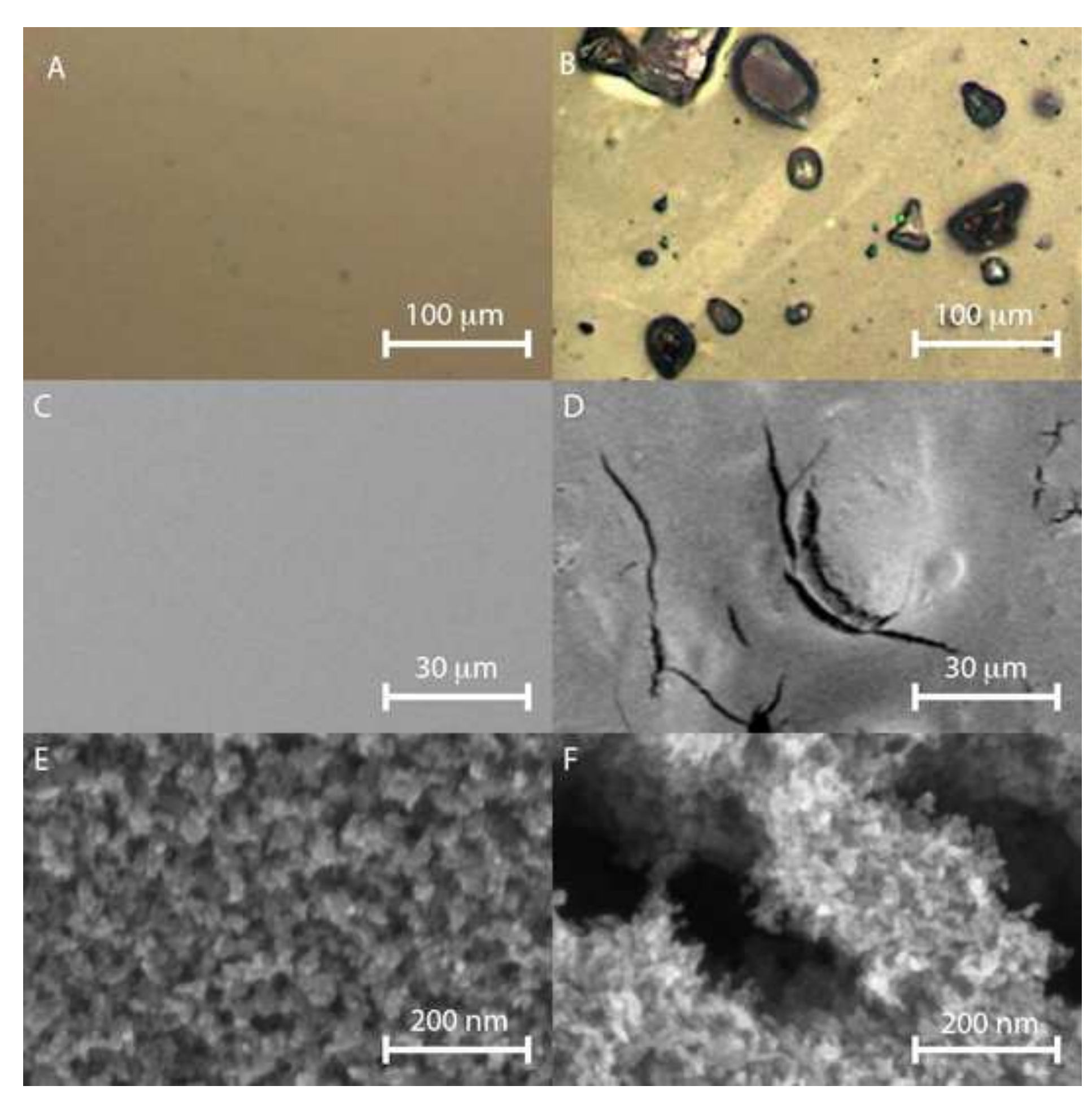

Figure 1

Figure 1
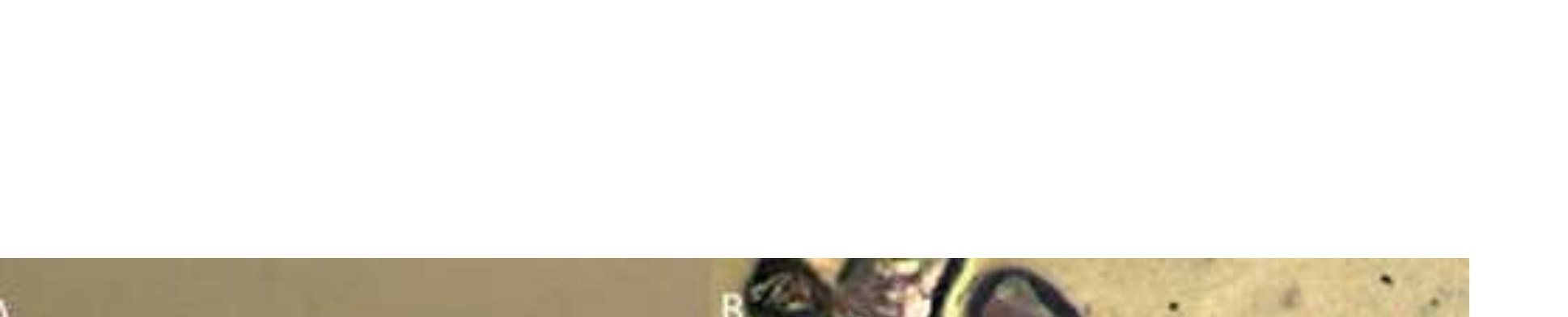

Pof



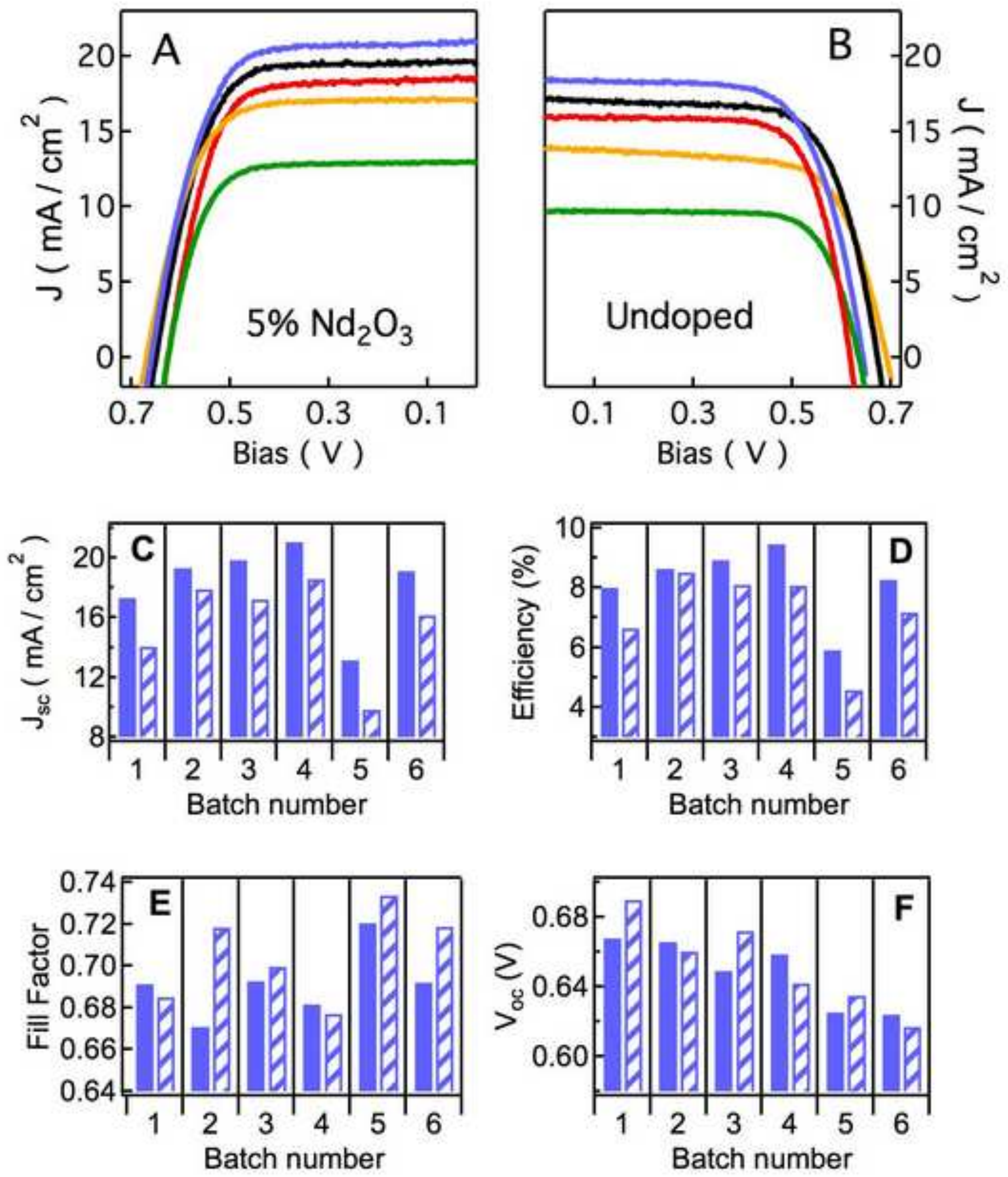


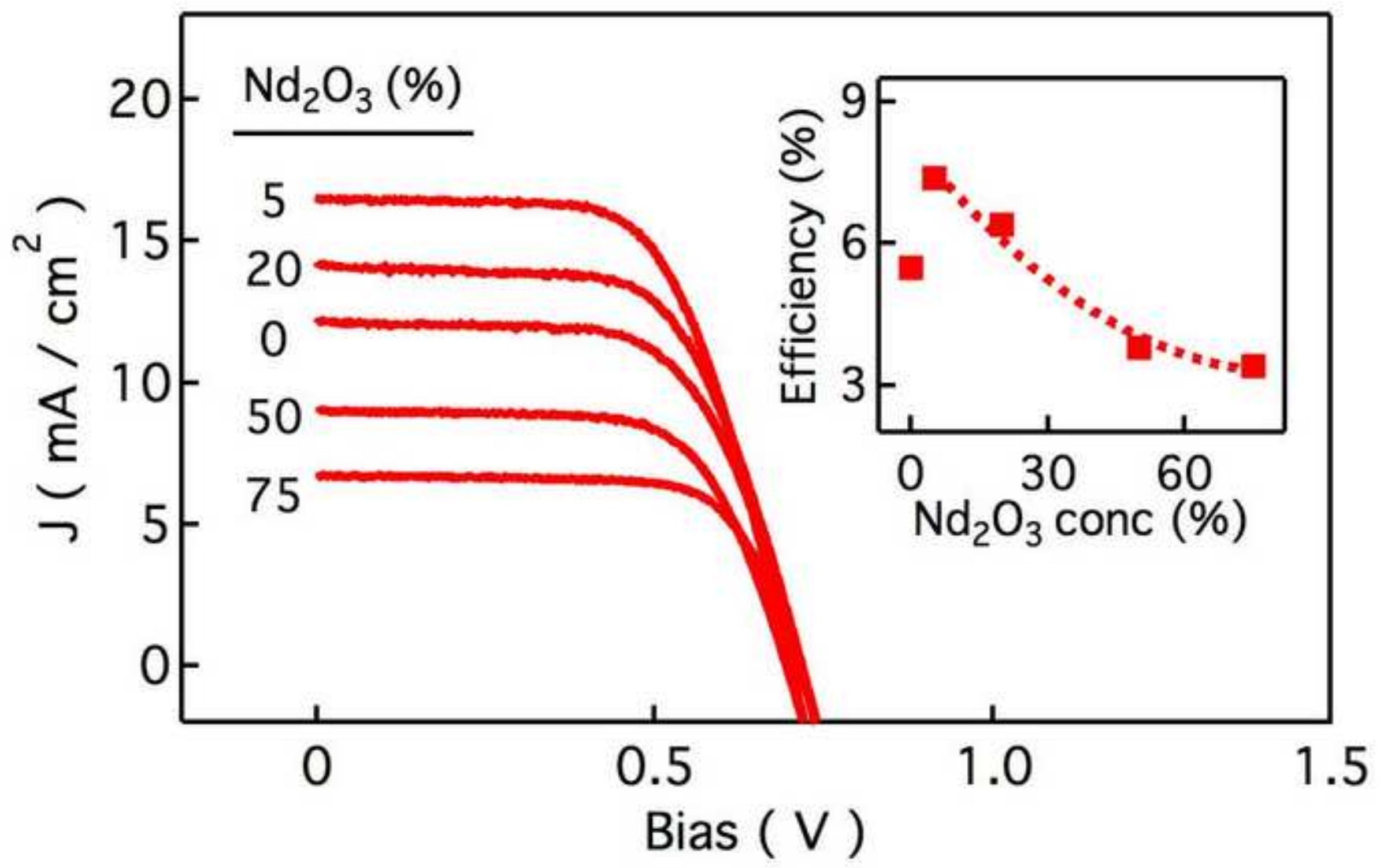



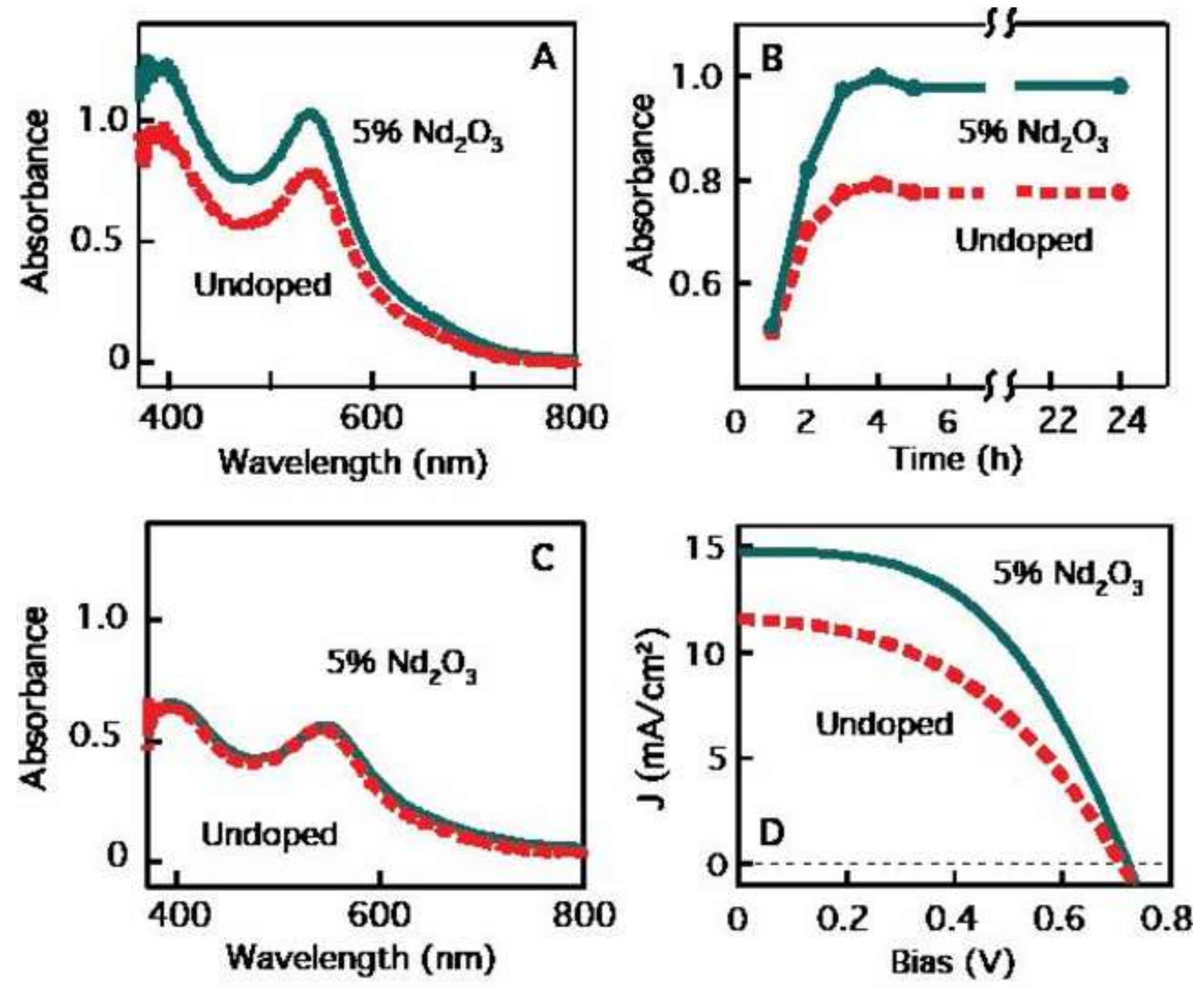


\section{$h v$}

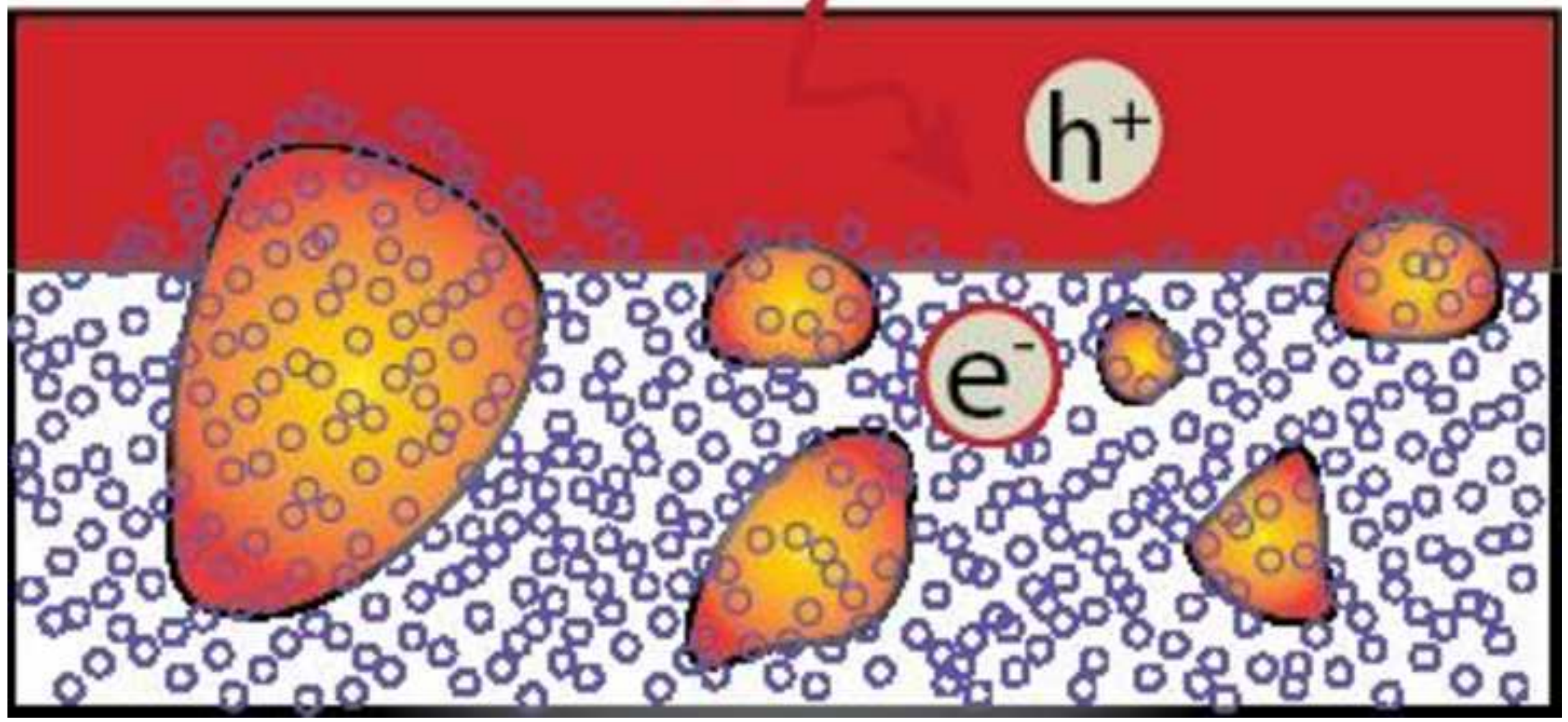

